J. Clin. Chem. Clin. Biochem.

Vol. 18, 1980, pp. 491-495

\title{
Determination of Cholic and Chenodeoxycholic Acid in Serum: Evaluation of Two Commercial Radioimmunoassay Methods
}

\author{
By $M$. Källberg and $P$. Tobiasson \\ Technical assistance: Marja Tjädermo \\ Department of Clinical Chemistry, University Hospital, S-581 85 Linköping, Sweden
}

(Received September 20, 1979/February 13, 1980)

\begin{abstract}
Summary: Commercially available radioimmunoassay kits for determination of serum cholic and chenodeoxycholic acid conjugates ("Glycocholic acid RIA kit", "Glycochenodeoxycholic acid RIA kit", Nordiclab Oy, Oulu, Finland) have been evaluated with respect to recovery, specificity and precision. The recovery, of the glycocholic acid method was low when performed according to the manufacturer's instructions, but could be raised to an acceptable level by using serum-based standards. However, the non-specific binding of serum samples varied considerably in the glycocholic acid method and would demand the use of individual blanks. The recovery of the glycochenodeoxycholic acid method was satisfactory and no inter-individual serum effect was discovered. The methods were considered sufficiently specific for their purposes, but precision was rather low for values within the lower normal range in both methods. We conclude that the glycochenodeoxycholic acid method is satisfactory for its purpose, but the glycocholic acid method needs to be modified.
\end{abstract}

\section{Bestimmung von Cholsäure und Chenodesoxycholsäure im Serum: Bewertung zweier käuflicher Radioimmunassay-Methoden}

Zusammenfassung: Käuflich erhältliche Radioimmunassay-Bestecks für die Bestimmung von Cholsäure- und Chenodesoxycholsäure-Konjugaten im Serum (Glycocholic acid RIA kit, Glycochenodeoxycholic acid RIA kit, Nordiclab Oy, Oulu, Finnland) wurden hinsichtlich Wiederfindung, Spezifität und Präzision bewertet. Die Wiederfindung mit der Glykocholsäure-Methode war niedrig, wenn sie nach Angaben des Herstellers ausgeführt wurde, konnte jedoch bei Verwendung von Standards auf Serumbasis auf einen annehmbaren Wert verbessert werden. Die unspezifische Bindung durch Serumproben wechselte jedoch beträchtlich bei der Glykocholsäure-Methode und erforderte individuelle Leerwerte. Die Wiederfindung mit der Glykochenodesoxycholsäure-Methode war zufriedenstellend und interindividuelle Serum-Effekte konnten nicht festgestellt werden. Die Methoden werden für ihren Zweck als ausreichend spezifisch erachtet, jedoch war die Präzision für beide Methoden für Werte im unteren Normalbereich eher gering. Wir folgern, daß die Glykochenodesoxycholsäure-Methode ihrem Zweck genügt, die Glykocholsäure-Methode jedoch der Modifikation bedarf.

\section{Introduction}

The interest in serum bile acid determinations has grown considerably during recent years and several studies have șown that raised levels of serum bile acids are sensitive indicators of impaired liver function (1). Furthermore, measurements of postprandial elevations of serum bile acids have been used for investigating the enterohepatic circulation of bile acids and have been proposed as a means of detecting bile acid malabsorption (2). Since the first rảdioimmunoassay for determination of conjugated cholic acid in serum was described by Simmonds et al. in 1973 (3), a number of similar radioimmunoassay techniques have been reported (summarized in 1. c. (4)). Recently radioimmunoassay kits for determination of glycocholic and glycochenodeoxycholic acid in serum (Nordiclab Oy, Finland) have become available. The purpose of this paper is a critical evaluation of these kits.

\section{Material and Methods}

Bile acids were purchased from Sigma (St. Louis, Mo.) and purity was checked by thin layer chromatography (5). Bile acid-free serum was prepared according to Schalm et al. (6). 


\section{Radioimmunoassays}

for gly'cocholic and glycochenodeoxycholic acid

The "Glycocholic acid RIA kit" and the "Glycochenodeoxycholic acid RIA kit" are manufactured by Nordiclab Oy, Oulu, Finland ${ }^{1}$ ). According to the manufacturer antibodies were raised in rabbits against gly cocholic and glycochenodeoxycholic acid coupled to bovine serum albumin. Tracers were $\left[{ }^{125} \mathrm{I}\right] \mathrm{his}-$ taminylcholy lglycine and [ ${ }^{125}$ I] histaminylchenodeoxycholylglycine. Each kit is supplied with standard solutions of gly cocholic or gly cochenodeoxycholic acid in ethanol $(950 \mathrm{ml} / \mathrm{l})$. covering the concentration range of $0.15-15 \mu \mathrm{mol} / 1$, together with control sera at two levels of bile acid concentration and contains materials sufficient for 100 tubes.

\section{Assay procedure}

The assays were performed according to the manufacturer's instructions. In the "Glycocholic acid RIA kit" $100 \mu \mathrm{l}$ of serum was extracted with $400 \mu \mathrm{l}$ of ethanol $(950 \mathrm{ml} / \mathrm{l})$ by vortexing for one minute. In the "Gly cochenodeoxycholic acid RIA kit" $20 \mu \mathrm{l}$ of serum was extracted with $1.00 \mathrm{ml}$ of ethanol $(950 \mathrm{ml} / \mathrm{l})$. After centrifugation $100 \mu \mathrm{l}$ portions of the extracts were transferred in duplicate to assay tubes. After evaporation the bile acids were dissolved in $200 \mu \mathrm{l}$ of tracer solution and $200 \mu \mathrm{l}$ of antibody solution was added. Tubes for measuring the nonspecific binding were prepared by adding $200 \mu \mathrm{l}$ of tracer solution to empty tubes which were further treated as sample tubes. The tubes were incubated at $+37^{\circ} \mathrm{C}$ for $1-2$ hours. Separation of free and antibody-bound antigen was accomplished by adding $500 \mu$ of polyethylene glycol solution (Carbowax 6000, final concentration $165 \mathrm{~g} / \mathrm{l}$ ) containing $\gamma$-globulin as a carrier protein. After centrifugation, radioactivity of the precipitates was measured for 5 minutes in a 16-channel gamma-counter (Nuclear Enterprises, Edinburgh, Scotland) giving a counting precision better than $1 \%$.

Straight line standard curves were obtained by a weighted linear regression analysis of logit $(B-N) /\left(B_{0}-N\right)$ against the logarithm of the concentration according to Rodbard (7) (B, antibodybound fraction; $B_{0}$, antibody-bound fraction at zero standard concentration; $N$, non-specific bound fraction). The fraction of $B_{0}$ was $0.62 \pm 0.06$ (mean $\pm S D, n=23$ ) of the total counts present in the assay.

Certain serum samples were also analyzed by radioimmunoassay methods for glycocholic and glycochenodeoxycholic acid conjugates developed in our own laboratory. These comparison methods were based essentially on the work of Demers $\dot{\&}$ Hepner (8) and Simmonds et al. (3). Tracers were gly co- $\left[{ }^{3} \mathrm{H}\right]$ cholic or glyco-[ $\left[{ }^{3} \mathrm{H}\right]$ chenodeoxycholic acid. Bile acid standards were prepared in bile acid-free serum as described by Schalm et al. (6). Standards or patient sera (the latter diluted 1:5 in phosphate buffer $10 \mathrm{mmol} / \mathrm{l}$ ) were added to assay tubes in $100 \mu \mathrm{l}$ aliquots followed by $100 \mu$ l of radiolabelled bile acid. Antiserum, diluted to a concentration at which a fraction of 0.40 of the tracer was bound in zero standard, was added in $200 \mu$ l aliquots and, after incubation for $2-24$ hours, antibody-bound and free bile acids were separated by ammonium sulphate precipitation. The precipitate was dissolved in distilled water and radioactivity was determined by liquid scintillation counting. Standard curves were prepared in the same way as for the Nordiclab methods. Within-run precision, as determined from duplicate analysis of 350 serum samples, was $6 \%(\mathrm{CV})$ and betweenrun precision, determined from 60 repetitive assays of control sera was $10 \%(\mathrm{CV})$ in both methods. The detection limit, calculated from the standard deviation of samples with low bile acid concentrations $(<0.25 \mu \mathrm{mol} / 1)$, was $0.06 \mu \mathrm{mol} / 1$ in the two comparison methods. Recovery of glycocholic and glycochenodeoxycholic acid was $94 \pm 5 \%$ (mean \pm SD) and $89 \pm 5 \%$ respectively. The specificity of the antisera of the comparison methods is shown in table 1.

1) Nordiclab Oy is represented in the Federal Republic of Germany by Biolab International, Schwanenweg 4,8081 Eching am See.
Tab. 1. Cross reactivity of bile acids with antisera of the comparison methods.

\begin{tabular}{|c|c|c|}
\hline \multirow[t]{2}{*}{ Bile acid } & \multicolumn{2}{|c|}{ Cross reactivity (\%) } \\
\hline & $\begin{array}{l}\text { Glycocholic } \\
\text { acid } \\
\text { antiserum }\end{array}$ & $\begin{array}{l}\text { Glycocheno- } \\
\text { deoxycholic } \\
\text { acid } \\
\text { antiserum }\end{array}$ \\
\hline Cholic & 20 & 1 \\
\hline Glycocholic & 100 & 4 \\
\hline Taurocholic & 75 & 1 \\
\hline Chenodeoxycholic & 0.5 & 30 \\
\hline Glycochenodeoxycholic & 4 & 100 \\
\hline Taurochenodeoxycholic & 3 & 100 \\
\hline
\end{tabular}

\section{Results}

\section{Standard curves}

Figure 1 shows typical standard curves for the Nordiclab methods. Both methods had their optimal measuring range for moderately elevated values of bile acids.

\section{Recovery}

Recovery of the "Glycocholic acid RIA kit" was determined by adding glycocholic acid to eight serum samples with initial glycocholic acid concentrations ranging from $0.1-1.0 \mu \mathrm{mol} / 1$ to raise the concentration by $1 \mu \mathrm{mol} / 1$. The recovery was $49 \pm 3 \%$ (mean \pm SD) when using the ethanol-based standards supplied with the kit. For many radioimmunoassays, however, it is necessary that the standards are prepared in a sample-like medium. Recovery was therefore tested using standards prepared in bile acid-free serum. Figure 2 shows the standard curves obtained with and without serum addition. The displacement of the serum-based curve reflected mainly losses in the extraction of the serum-based standards. The recovery found using serum-based standards was $98 \pm 8 \%$ and the use of serum-based standards thus seemed necessary. However, the non-specific binding of different serum samples varied considerably. In one analytic run the counts of the non-specific binding varied in 14 different serum samples between 53909170 counts $/ \mathrm{min}$. It may be calculated that if a sample contained $0.8 \mu \mathrm{mol} / 1$ of glycocholic acid (medical decision limit) this variation of the non-specific binding would produce results varying between $0.4-1.4 \mu \mathrm{mol} / 1$.

Recovery of the "Glycochenodeoxycholic acid RIA kit" was tested in the same way as described above. The recovery found was $90 \pm 10 \%$ (mean \pm SD). The method was tested using ethanol-based standards as well as serum-based standards, but no significant difference was detected between the curves prepared with and without the addition of serum. In the further experiments with the "Glycochenodeoxycholic acid RIA kit", however, we used standards prepared in bile acid-free serum. No interindividual variation of the non-specific binding of serum samples was detected in this,method. 

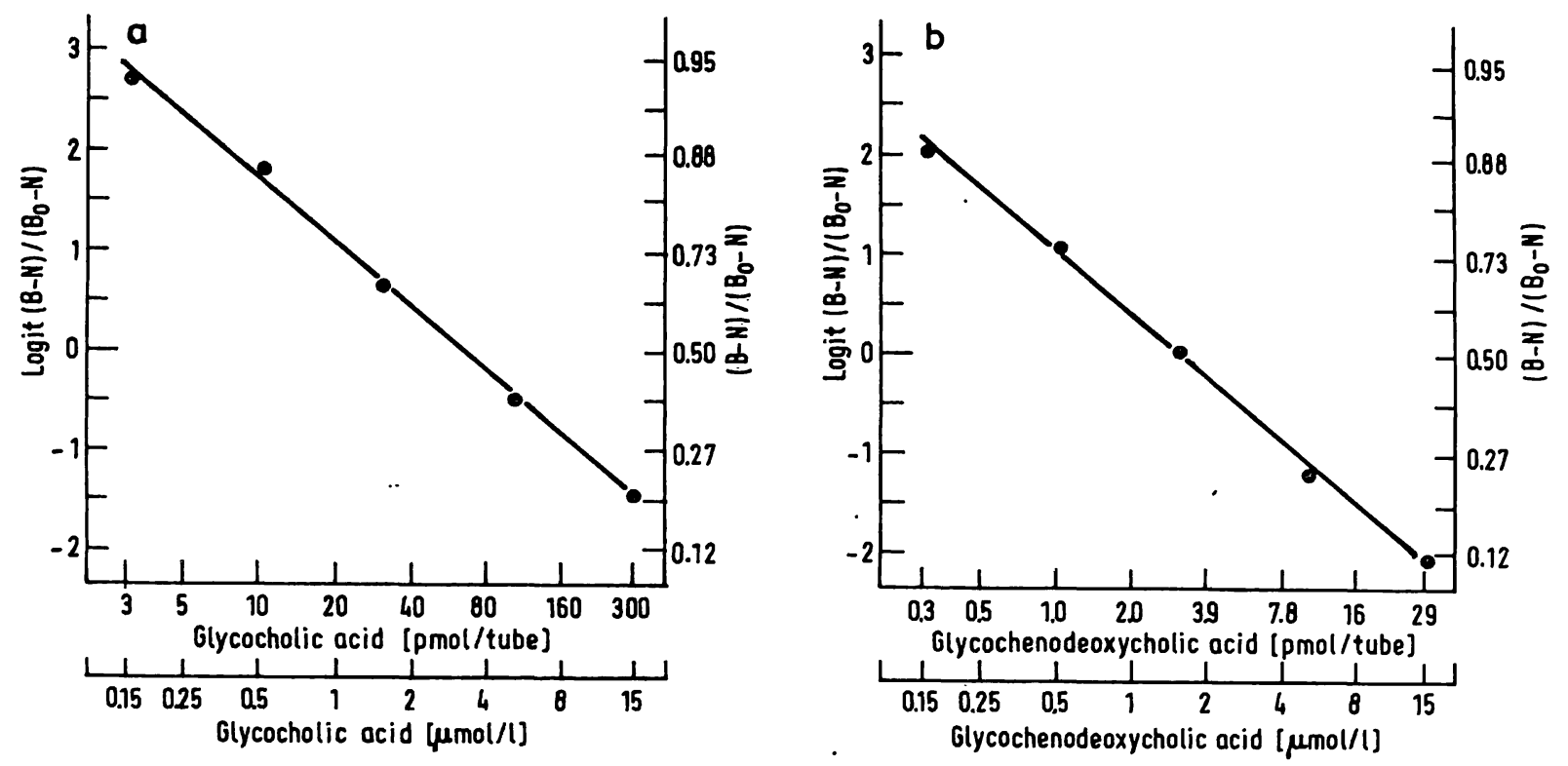

Fig. 1. Typical standard curves produced by the "Glychocholic acid RIA kit" (a) and by the "Glycochenodeoxycholic acid RIA kit" (b) using ethanol-based standards. $B=$ antibody-bound fraction $B_{0}=$ antibody-bound fraction at zero standard concentration $\mathrm{N}=$ non-specific bound fraction.

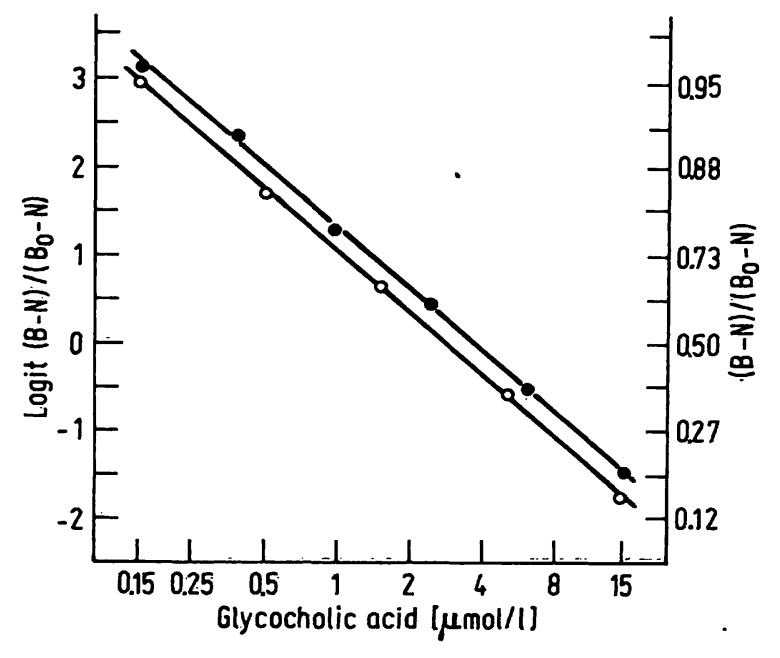

Fig. 2. Standard curves of the "Glycocholic acid RIA kit":

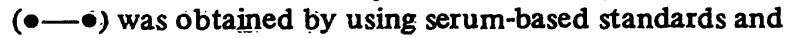
(०-0) was obtained by using the standards supplied with the kit. $B=$ antibody-bound fraction $B_{0}=$ antibodybound fraction at zero standard concentration $\mathrm{N} \equiv$ nonspecific bound fraction measured by omitting the antibody from the respective zero standard tubes.

\section{Specificity}

Cross-reactivity was calculated at $50 \%$ displacement of label (9) and figures are given in table 2. The antiserum to glycocholic acid cross-reacted only to a small extent with unconjugated and conjugated chenodeoxycholic acid and exhibited a higher sensitivity to taurine-conjugated cholic acid than to glycine-conjugated cholic acid. The antiserum to glycochenodeoxycholic acid had
Tab. 2. Cross reactivity of bile acids with antisera of the glycocholic and glycochenodeoxycholic acid RIA kits.

\begin{tabular}{lcccc}
\hline Bile acid & \multicolumn{3}{l}{ Cross reactivity (\%) } \\
& $\begin{array}{l}\text { "Glycocholic } \\
\text { acid }\end{array}$ & $\begin{array}{l}\text { "Glycocheno- } \\
\text { deoxycholic }\end{array}$ \\
& RIA kit" & \multicolumn{3}{c}{ acid RIA kit" } \\
\hline Cholic & 60 & $(100)$ & 0.4 & $(0.1)$ \\
Glycocholic & 100 & $(100)$ & 0.3 & $(0.8)$ \\
Taurocholic & 180 & $(100)$ & 0.6 & $(0.4)$ \\
Chenodeoxycholic & 1.9 & $(1.5)$ & 33 & $(100)$ \\
Glycochenodeoxycholic & 3.0 & $(4.2)$ & 100 & $(100)$ \\
Taurochenodeoxycholic & 4.2 & $(1.3)$ & 90 & $(50)$
\end{tabular}

Within parenthesis are the figures given by the manufacturer. Cross reactivity was determined using one batch of antiserum for each of the two kits.

almost the same sensitivity to the two conjugates of chenodeoxycholic acid, but a lower sensitivity to unconjugated chenodeoxycholic acid and a low sensitivity to cholic acid and its conjugates.

\section{Precision}

Figures for within-run precision were determined from duplicate determinations of serum samples and are shown in table 3 . For both methods precision was acceptable for values in the upper normal range and for elevated values, but rather low for values within the lower normal range. As calculated from the standard deviation of samples with low bile acid concentrations $(<0.5 \mu \mathrm{mol} / 1)$, the detection limit was $0.10 \mu \mathrm{mol} / \mathrm{l}$ in the "Glycocholic acid RIA kit" and $0.08 \mu \mathrm{mol} / \mathrm{l}$ in the "Glycochenodeoxycholic acid RIA kit". 
Tab. 3. Within-run precision of the Nordiclab methods determined from duplicate determinations.

\begin{tabular}{lcccccc}
\hline & \multicolumn{3}{c}{ "Glycocholic acid RIA kit" } & \multicolumn{3}{c}{ "Glycochenodeoxycholic acid RIA kit" } \\
\hline $\mathrm{n}$ & 44 & 25 & 40 & 18 & 45 & 55 \\
Range $(\mu \mathrm{mol} / \mathrm{l})$ & 0.5 & $0.5-2.0$ & $2.0-15.0$ & $<0.5$ & $0.5-2.0$ & $2.0-15.0$ \\
$\mathrm{x}(\mu \mathrm{mol} / \mathrm{l})$ & 0.28 & 1.2 & 5.5 & 0.29 & 1.11 & 5.9 \\
$\mathrm{SD}(\mu \mathrm{mol} / \mathrm{l})$ & 0.05 & 0.13 & 0.54 & 0.04 & 0.09 & 0.68 \\
$\mathrm{CV}(\%)$ & 18 & 11 & 10 & 15 & 8 & 11 \\
\hline
\end{tabular}

\section{Reference values}

Reference values were established using sera from 57 healthy fasting individuals, age range 18-71 years, median age 25 years. Using ethanol-based standards $65 \%$ of these sera had values less than zero in the glycocholic acid method, i. e. the bound fraction was greater than that of the zero standard. The mean and SD for glycocholic acid were 0.04 and $0.08 \mu \mathrm{mol} / 1$ respectively, but using serum-based standards the corresponding values were 0.33 and $0.21 \mu \mathrm{mol} / 1$. As calculated from mean + $2 \mathrm{SD}$ the upper reference value using serum-based standards was $0.8 \mu \mathrm{mol} / 1$, i. e. the same value as stated by the manufacturer. The mean and SD for glycochenodeoxycholic acid were 0.66 and $0.39 \mu \mathrm{mol} / 1$ respectively and the upper reference value, as calculated above, was $1.4 \mu \mathrm{mol} / 1$. The manufacturer stated an upper reference limit of $1.0 \mu \mathrm{mol} / 1$ for glycochenodeoxycholic acid.

\section{Correlation}

Ninety sera with different glycocholic acid concentrations were analyzed and the correlation between values obtained by our comparison method and by the Nordiclab method using serum-based standards is shown in figure 3 . The Nordiclab method gave significantly higher results, the slope of the regression line (1.23) being significantly different from $1(\mathrm{p}<0.001)$. The intercept (0.006) was not significantly different from 0 .

For glycochenodeoxycholic acid 90 different serum samples were analyzed and figure 4 depicts the correlation between values obtained by our comparison method and by the "Glycochenodeoxycholic acid RIA kit". The commercial method gave significantly higher values than our comparison method as the slope (1.27) was significantly different from $1(\mathrm{p}<0.001)$. The intercept $(-0.038)$ was not significantly different from 0 .

\section{Discussion}

In the Nordiclab methods a composite sum of conjugated and unconjugated cholic and chenodeoxycholic acid is measured. In fasting normal subjects serum bile acid concentrations are low and approximately $50 \%$ (10) are conjugated with either glycine or taurine. The ratio of glycine-conjugates to taurine-conjugates is about $2: 1$ to $3: 1$. Thus, it may be calculated that in normal fasting sera the values obtained with the "Glycocholic

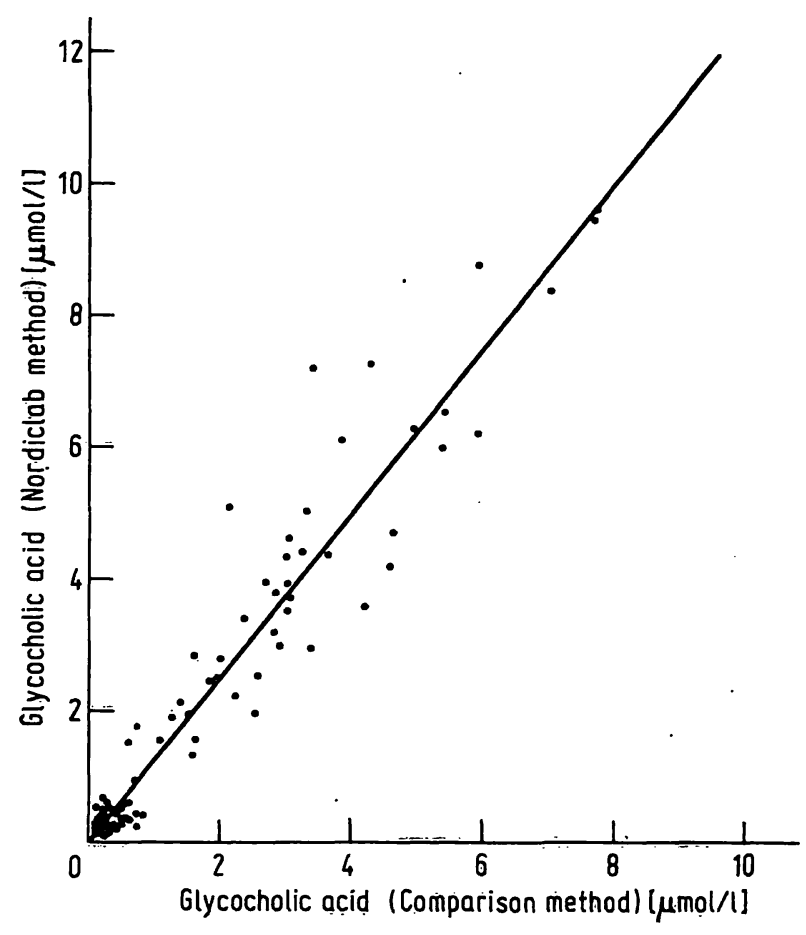

Fig. 3. Comparison of results for serum analysis of glycocholic acid (GCA) obtained with the "Glycocholic acid RIA kit" (Nordiclab method) and the radioimmunoassay method for gly cocholic acid developed in our laboratory (comparison method). The relation found was:

GCA $_{\text {Nordiclab method }}=1.23 \times$ GCA $_{\text {Comparison method }}$ $+0.006$

Correlation coefficient 0.96

acid RIA kit" will be approximately $200 \%$ of the actual concentration of glycine-conjugated cholic acid and about $150 \%$ of the true concentrations of the two conjugates of cholic acid. The "Glycochenodeoxycholic acid RIA kit" produces results that are about $150 \%$ of the real concentration of glycine-conjugated chenodeoxycholic acid and approximately $120 \%$ of the actual concentrations of taurine- plus glycine-conjugated chenodeoxycholic acid in these sera. In patients with liver disease serum bile acids may be grossly elevated, up to 100 times the normal concentration or more, and this increase consists largely of conjugated bile acids. In these sera the ratio of glycine-conjugated to taurineconjugated bile acids is usually lower than in normal sera. Values obtained with the "Glycocholic acid RIA kit" in these sera will be about $300 \%$ of the true con- 


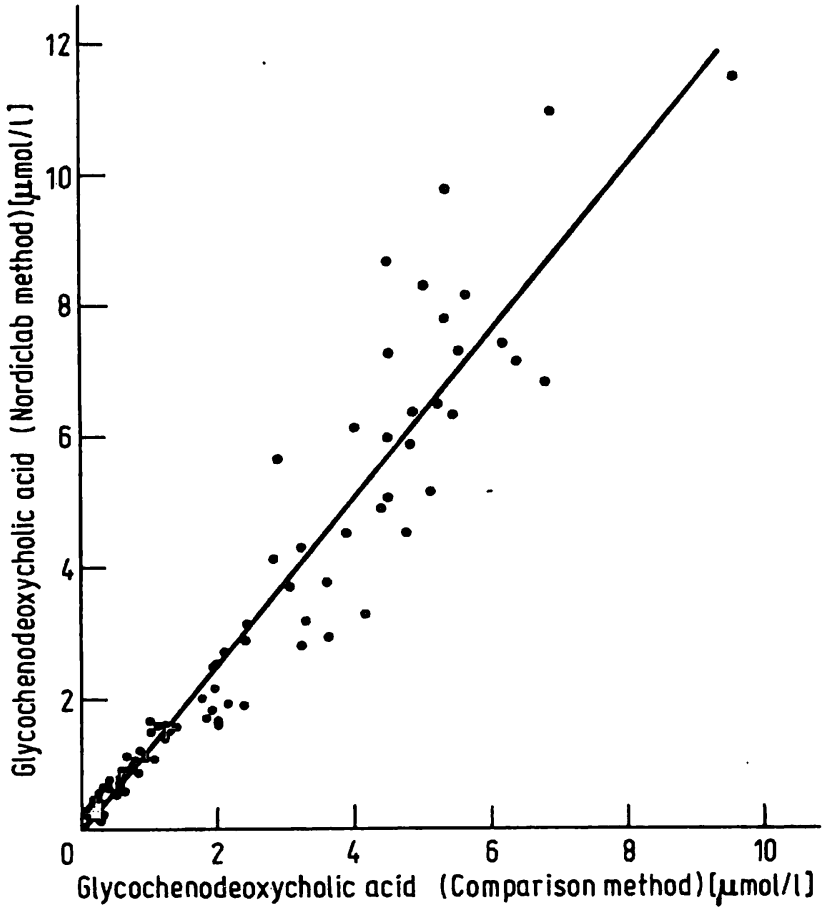

Fig. 4. Comparison of results for serum analy sis of gly cochenodeoxycholic acid (GCD) obtained with the "Glycochenodeoxycholic acid RIA kit" (Nordiclab method) and the radioimmunoassay method for glycochenodeoxycholic acid developed in our laboratory (comparison method). The relation found was

$\mathrm{GCD}_{\text {Nordiclab method }}=1.27 \times \mathrm{GCD}_{\text {Comparison method }}$ $-0.038$

Correlation coefficient $=0.96$

centration of glycine-conjugated cholic acid and approximately $140 \%$ of the actual concentration of the two conjugates of cholic acid. The "Glycochenodeoxycholic acid RIA kit" will produce values about $200 \%$ of the true concentration of glycine-conjugated chenodeoxycholic acid in these pathological sera. However, these values will be close to the true concentra- tions of conjugates of chenodeoxycholic acid (95$100 \%$ ).

The Nordiclab kits are provided with a bile acid standard prepared in ethanol. Our investigations clearly show that the glycocholic acid method should be supplied with serum-based standards to produce more accurate results. However, the interindividual variation of the nonspecific binding of serum samples demands further development of the method, e. g. raising the analytical sensitivity of the method to allow higher sample dilution. The glycochenodeoxycholic acid method has a higher analytical sensitivity than the glycocholic acid method. This allows higher sample dilution and therefore the use of serum-based standards does not seem necessary.

In both Nordiclab methods only sera with substantially raised bile acid concentrations need to be diluted. This advantage is, however, balanced by less precise measurements of values within the normal range. Accurate determinations of postprandial elevations of serum bile acids can therefore hardly be obtained.

Raised levels of serum bile acids are considered a sensitive indicator of impaired liver function. The two primary bile acids, cholic and chenodeoxycholic acid, can be determined separately by radioimmunoassay, since the cross-reactivity between these bile acids are usually less than $10 \%$. This is of clinical importance, as in cholestatic liver disorders, cholic acid is the major bile acid found in serum, whereas in alcoholic liver disease and cirrhosis a predominance of chenodeoxycholic acid in serum is usually found $(11,12,13)$.

\section{Acknowledgement}

We thank Warner-Lambert (Sweden) AB, Gothenburg, Sweden and Nordiclab Oy, Oulu, Finland for financial support in performing this investigation.

\section{Referencès}

1. Javitt, N. B. (1977), Clin. Gastroenterol. 6, 219-226.

2. LaRusso, N. F., Korman, M. G., Hoffman, N. E. \& Hofmann, A. F. (1974), N. Engl. J. Med. 291, 689-692.

3. Simmonds, W. J., Korman, M. G., Go, V. L. W. \& Hofmann, A. F. (1973), Gastroenterology 65,705-711.

4. Matern, S. \& Gerok, W. (1978), Zschr. Gastroenterol. 16, $162-176$.

5. Gregg, J. A. (1966), J. Lipid Res. 7, 579-581.

6. Schalm, S. W., van Berge-Henegouwen, G. P., Hofmann, A. F., Cowen, A. E. \& Turcotte, J. (1977), Gastroenterology $73,285-290$.

7. Hewlett-Packard Radioimmunoassay Pac, Volume No. 1 for HP 9830 A, Part No. 09830-75329, Hewlett-Packard Calcula-

tor Products Division P. O. Box 301, Loveland, Colorado 80537, USA.

8. Demers, L. M. \& Hepner, G. (1976), Clin. Chem. 22, 602606.

9. Abraham, G. E. (1969), J. Clin. Endocrinol. 29, 866-870.

10. Makino, I., Nakagawa, S. \& Mashimo, K. (1969), Gastroenterology 56, 1033-1039.

11. Pennington, C. R., Ross, P. E. \& Bouchier, I. A. D. (1977), Gut 18, 903-908.

12. Tobiasson, P. \& Boeryd, B. Accepted for publication in Scañd. J. Gastroenterol.

13. Milstein, H. J., Bloomer, J. R. \& Klatskin, G. (1976), Am. J. Dig. Dis. $21,281-285$.

Per Tobiasson, M. D. 
